\title{
Late-onset group B streptococcal disease is a rare but devastating disease
}

\author{
KL Hon ${ }^{1,2}$ *, MB, BS, MD, Karen KY Leung', MB, BS, MRCPCH, Alexander KC Leung 3 , FRCP(UK), FRCPCH, \\ $\mathrm{KW} \mathrm{So}{ }^{2}, \mathrm{MB}, \mathrm{BS}, \mathrm{FRCPCH}$ \\ ${ }^{1}$ Department of Paediatrics and Adolescent Medicine, The Hong Kong Children's Hospital, Hong Kong \\ ${ }^{2}$ Department of Paediatrics, The Chinese University of Hong Kong, Hong Kong \\ ${ }^{3}$ Department of Pediatrics, The University of Calgary and the Alberta Children's Hospital, Calgary, Alberta, Canada
}

Hong Kong Med J 2021;27:229-30

*Corresponding author: ehon@hotmail.com

\section{https://doi.org/10.12809/hkmj198286}

Group B streptococcus (GBS) or Streptococcus agalactiae is an organism colonising the maternal gastrointestinal and genital tracts which may lead to significant morbidities and mortalities in infants. ${ }^{1-4}$ Universal screening of pregnant mothers for GBS carriage has been implemented in Hong Kong since 2012 but we continue to encounter late-onset GBS disease. ${ }^{4}$ This commentary reviews the epidemiology, risk factors, mortality, and morbidity of late-onset GBS especially pertinent to Hong Kong.

A 2017 global study revealed some 21.7 million pregnant women carry GBS and infections cause 150000 preventable stillbirths and infant mortality annually. ${ }^{5}$ Before 2012, a risk-based screening strategy was used to select patients for intrapartum antibiotics prophylaxis and the incidence of earlyonset GBS disease was 0.58 to 1.1 per 1000 live births in Hong Kong. ${ }^{3}$ A universal screening swab-based screening programme was implemented in Hong Kong after $2012 .{ }^{6}$ The worldwide incidence of lateonset GBS disease is 0.26 per 1000 live births, while the incidence in Hong Kong was 0.38 per 1000 live births despite intrapartum antibiotics. ${ }^{7,8}$

Maternal risk factors for early-onset GBS disease include vaginal GBS colonisation, GBS bacteriuria, intrapartum maternal fever, and chorioamnionitis. Overall $18 \%$ of women worldwide and $21.8 \%$ of Hong Kong mothers are colonised. ${ }^{5,6}$ A local study has shown that highly educated and socially advantaged professional women were more likely to be carriers, and that there were no differences in the colonisation rate between Hong Kong and mainland Chinese citizens. ${ }^{9}$ The risk of neonatal GBS septicaemia for infants born to women diagnosed with vaginal GBS colonisation can be as high as 25 times compared with women who are not colonised. ${ }^{4}$ Vertical transmission of GBS occurs after rupture of the amniotic membranes or after the onset of labour. The risk of early-onset GBS disease is extremely low if the mother is undergoing planned caesarean section in the absence of labour and with intact membranes. ${ }^{10}$ Other risk factors include prematurity, premature or prolonged rupture of amniotic membranes, multiple gestation pregnancy, and prior delivery of an infant with GBS disease. ${ }^{3,11}$
For late-onset GBS disease, in contrast to early-onset GBS disease, vaginal GBS colonisation is not a crucial factor. Reported risk factors includes prematurity, exposures to colonised family members and medical equipment. The use of maternal intrapartum chemoprophylaxis has been shown to be ineffective in the prevention of late-onset GBS disease. ${ }^{12}$ The probability of recurrence after the first episode of GBS infection is between $1 \%$ and $6 \% .{ }^{4}$

The mortality rate of invasive GBS diseases ranges from $5 \%$ to $37 \% .^{3,12-15}$ Late-onset GBS disease are associated with higher morbidity and significant neurodevelopmental impairments. ${ }^{13,16}$ As lateonset GBS disease is not a notifiable disease in Hong Kong it is difficult to comment on the local prevalence. Only two case reports had been found in the literature and both cases were managed in the intensive care unit. Both cases survived the episode of GBS disease, however, long-term morbidity was not mentioned. ${ }^{4,14,17}$

In the management of an infant with GBS infection, penicillin $G$ is generally recommended for the treatment of GBS infection as well as for intrapartum prophylaxis to prevent early-onset GBS disease. ${ }^{18}$ However, tolerance to penicillin in penicillin-sensitive GBS strains has been reported and might be a contributing factor of treatment failure, necessitating very high dosages or change of antibiotics. ${ }^{18,19}$

Late-onset GBS disease is not preventable despite the use of intrapartum antibiotics for selective high-risk patients. ${ }^{15}$ Treatment with rifampin can be tried to eradicate the colonisation but variable efficacy is variable. ${ }^{20}$

The timing of the universal GBS screening programme in Hong Kong, which at present is recommended to be performed between 35 to 37 weeks' gestation, might need to be reviewed. ${ }^{6}$ The latest American College of Obstetricians and Gynecologists suggested that the optimal window for antenatal screening is at 36 to 37 weeks' gestation; as the correlation between antenatal GBS colonisation results and colonisation status at the time of delivery decreases significantly when the culture-to-birth interval is longer than 5 weeks. ${ }^{21,22}$ 
Given the lack of an effective solution for preventing GBS disease, administration of an effective vaccine in the third trimester of pregnancy could provide a sensible and cost-effective solution in all settings. It is estimated a GBS vaccine with $80 \%$ efficacy and 90\% coverage could prevent 108000 fetal and infant deaths. ${ }^{5}$ The vaccine will protect neonates from GBS disease through transplacental transfer of antibodies to the fetus in utero. There are a few potential vaccines in development, and some are already undergoing Phase I and II trials; however, studies are still in progress to assess the optimal dose, need for adjuvant, immunogenicity in pregnant women, placental transfer and persistence in babies. ${ }^{5,23}$

The widespread use of intrapartum antibiotics has effectively reduced the rate of early-onset GBS disease, but not the rate of late-onset GBS disease. Although it is uncommon in Hong Kong, late-onset GBS disease is a serious condition with significant consequences, including stillbirths, and high infant mortality and morbidity. At present, effective ways to reduce late-onset infection are limited, but with the development of a safe and effective maternal vaccination, it is a potentially a preventable infection.

\section{Author contributions}

All authors contributed to the concept or design of the study, acquisition of the data, analysis or interpretation of the data, drafting of the manuscript, and critical revision of the manuscript for important intellectual content. All authors had full access to the data, contributed to the study, approved the final version for publication, and take responsibility for its accuracy and integrity.

\section{Conflicts of interest}

As an editor of the journal, KL Hon was not involved in the peer review process. Other authors have disclosed no conflicts of interest.

\section{Funding/support}

This commentary received no specific grant from any funding agency in the public, commercial, or not-for-profit sectors.

\section{References}

1. Huang S, Liu X, Lao W, et al. Serotype distribution and antibiotic resistance of Streptococcus pneumoniae isolates collected at a Chinese hospital from 2011 to 2013. BMC Infect Dis 2015;15:312.

2. Wang P, Ma Z, Tong J, et al. Serotype distribution, antimicrobial resistance, and molecular characterization of invasive group B Streptococcus isolates recovered from Chinese neonates. Int J Infect Dis 2015;37:115-8.

3. Chan SH, Lau SP, Fok TF, Liang ST. Early onset neonatal group B streptococcal infection in Hong Kong. Asia Oceania J Obstet Gynaecol 1986;12:341-6.

4. Hon KL, Chan KH, Ko PL, So KW, Leung AK. Late onset Streptococcus agalactiae meningitis following early onset septicemia: a preventable disease? Case Rep Pediatr 2017;2017:8418105.

5. Seale AC, Bianchi-Jassir F, Russell NJ, et al. Estimates of the burden of Group B Streptococcal disease worldwide for pregnant women, stillbirths, and children. Clin Infect Dis 2017;65(Suppl 2):S200-19.

6. Ma TW, Chan V, So $\mathrm{CH}$, et al. Prevention of early onset group B streptococcal disease by universal antenatal culture-based screening in all public hospitals in Hong Kong. J Matern Neonatal Med 2018;31:881-7.

7. Madrid L, Seale AC, Kohli-Lynch M, et al. Infant Group B streptococcal disease incidence and serotypes worldwide: systematic review and meta-analyses. Clin Infect Dis 2017;65(Suppl 2):S160-72.

8. Rivera L, Sáez-Llorens X, Feris-Iglesias J, et al. Incidence and serotype distribution of invasive group B streptococcal disease in young infants: a multi-country observational study. BMC Pediatr 2015;15:143.

9. Tsui MH, Ip M, Ng PC, Sahota DS, Leung TN, Lau TK. Change in prevalence of group B Streptococcus maternal colonisation in Hong Kong. Hong Kong Med J 2009;15:4149.

10. Prevention of early-onset neonatal group B Streptococcal disease: Green-top Guideline No. 36 [editorial]. BJOG 2017;124:e280-305.

11. Schrag S, Gorwitz R, Fultz-Butts K, Schuchat A. Prevention of perinatal group B streptococcal disease. Revised guidelines from CDC. MMWR Recomm Rep 2002;51:1-22.

12. Berardi A, Rossi C, Lugli L, et al. Group B streptococcus late-onset disease: 2003-2010. Pediatrics 2013;131:e361-8.

13. Libster R, Edwards KM, Levent $F$, et al. Long-term outcomes of group B streptococcal meningitis. Pediatrics 2012;130:e8-15.

14. Hon KL, Chow TC, Cheung TS, et al. Severe Group A and Group B Streptococcus diseases at a pediatric ICU: are they still sensitive to the penicillins? Curr Clin Pharmacol 2020;15:125-31.

15. Jordan HT, Farley MM, Craig A, et al. Revisiting the need for vaccine prevention of late-onset neonatal group B streptococcal disease: a multistate, population-based analysis. Pediatr Infect Dis J 2008;27:1057-64.

16. Bartlett AW, Smith B, George CR, et al. Epidemiology of late and very late onset Group B Streptococcal disease: fifteen-year experience from two Australian tertiary pediatric facilities. Pediatr Infect Dis J 2017;36:20-4.

17. Chan LT, Law K, Law CW, Lee WH. Late-onset group B streptococcal cellulitis in a premature infant. HK J Paediatr 2010;15:48-51.

18. Heelan JS, Hasenbein ME, McAdam AJ. Resistance of group B streptococcus to selected antibiotics, including erythromycin and clindamycin. J Clin Microbiol 2004;42:1263-4.

19. Betriu C, Gomez M, Sanchez A, Cruceyra A, Romero J, Picazo JJ. Antibiotic resistance and penicillin tolerance in clinical isolates of group B streptococci. Antimicrob Agents Chemother 1994;38:2183-6.

20. Thomas SR, Dawoud T, Doss I, Al-Salam Z. Recurrent late-onset group B streptococcus sepsis in a neonate from breast milk. J Clin Neonatol 2017;6:192-4.

21. Puopolo KM, Lynfield R, Cummings JJ, Committee on Fetus and Newborn and Committee on Infectious Diseases. Management of infants at risk for group B Streptococcal disease. Pediatrics 2019;144:e20191881.

22. Hon KL, Fu A, Leung TF, et al. Cardiopulmonary morbidity of streptococcal infections in a PICU. Clin Respir J 2015;9:45-52.

23. Heath PT. Status of vaccine research and development of vaccines for GBS. Vaccine 2016;34:2876-9. 